\title{
Automatic cruise system for water quality monitoring
}

\author{
Chengyun Zhu ${ }^{1,2}$, Xingqiao Liu' ${ }^{1 *}$, Hailei Chen ${ }^{1}$, Xiang $\operatorname{Tian}^{1}$ \\ (1. Jiangsu University, School of Electrical and Information Engineering, Zhenjiang 212013, China; \\ 2. Yancheng Teachers University, School of New Energy and Electronic Engineering, Yancheng 224005, China)
}

\begin{abstract}
The range of unit fixed-point measurement on water quality monitoring system is limited, and the cost for multipoint measurement is high. In order to solve these problems, the automatic cruise system for water quality monitoring was designed. Sage-Husa adaptive Kalman filtering algorithm was adopted to correct the error in GPS positioning. The boat was equipped with ship control module, water quality parameters acquisition module, power-supply module, GPS module and GPRS-DTU packet data transmission module. An Android application was developed so that individual users can use smartphone to communicate with the boat at all time and places. The results show that the boat can basically cruise in the set route to monitor the water quality. In a $4 \mathrm{~m}^{2}$ aquatic plants areas, the dissolved oxygen monitored in different time were about $10.2 \%$, $8.5 \%$ and $8.3 \%$, respectively, higher than other areas, and the $\mathrm{pH}$ values were $4.1 \%, 3.8 \%$ and $3.7 \%$ higher than those in other waters, which shown that plants photosynthesis released oxygen consumption of carbon dioxide will affect the dissolved oxygen content and $\mathrm{pH}$ value. This system can widen the measurement range, and lower the measuring cost that can be widely used in the water quality monitoring in aquaculture and river management.
\end{abstract}

Keywords: water quality monitoring, GPS, automatic cruise, Android mobile client DOI: $10.25165 /$ j.jjabe.20181104.2658

Citation: Zhu C Y, Liu X Q, Chen H L, Tian X. Automatic cruise system for water quality monitoring. Int J Agric \& Biol Eng, 2018; 11(4): 244-250.

\section{Introduction}

Water quality monitoring, an important part in aquaculture, is gradually transmitted from artificial experience-based monitoring to online real time monitoring ${ }^{[1,2]}$. Because one measurement in a fixed location cannot represent all the water quality information of a large fish pond ${ }^{[3]}$, so the distribution networks with more measurement nodes is required ${ }^{[4,5]}$. The multipoint measurement network requires a lot of capital and human resource investments for installation, maintenance, and operation of monitoring equipment. Therefore, within a limited financial budget and human capital, design an automatic cruise water quality monitoring system to solve this problem is very important.

In recent years, many studies ${ }^{[6-8]}$ have focused on aquaculture water quality monitoring, from different scientific points of view. Luo et al. ${ }^{[9]}$ designed a multi-parameters monitoring system based on wireless network, the system can realize real-time monitoring on dissolved oxygen, $\mathrm{pH}$, temperature, and ammonia nitrogen content in the water. Dong et al. ${ }^{[10]}$ explored a smart water quality monitoring system, the water quality parameters was measured by wireless sensor network. Chung et al. ${ }^{[11]}$ designed a wireless sensor network (WSN) with deployed field servers, which collected the water quality parameters information from a large area of waters to detect water pollution. Sicard et al. ${ }^{[12]}$ designed a paper-based sensors and a novel smart-phone application for on-site quantification of colorimetric readouts as an ultra-low cost solution to monitoring water quality. However, most of them

Received date: 2016-06-19 Accepted date: 2017-05-16

Biographies: Chengyun $\mathrm{Zhu}, \mathrm{PhD}$ candidate, research interest: agricultural electrification and automation, Email: zhucy@yctu.edu.cn; Hailei Chen, PhD candidate, research interest: agricultural electrification and automation, Email: 645356549@qq.com; Xiang Tian, PhD candidate, research interest: agricultural electrification and automation, Email: auzn0009@163.com.

*Corresponding author: Xingqiao Liu, PhD, Professor, research interest: agricultural electrification and automation; Mailing address: School of Electrical and Information Engineering of Jiangsu University, 301 Xuefu Road, Zhenjiang 212013, Jiangsu, China. Phone: +86-13775549460; Email: xqliu@ujs.edu.cn. adopted fixed-point or multipoint measurement, the range of fixed-point measurement is limited, and multipoint measurement can accurately measure the water quality, but the cost is higher, so ordinary farmers are beyond accepting.

In order to meet the requirement of low cost and accurate access to water quality measuring in large area, this paper presents a design scheme of automatic cruise measurement system that adopts mobile single point measurement instead of multi-point distributed measurement to send the collected water quality information and the location information to the host computer through wireless transmission.

\section{Material and methods}

\subsection{Improved Kalman filtering algorithm}

Because the aquatic plants may exist on the surface of fish pond and the navigation accuracy of the boat should be higher to prevent the boat deviates from the set path to nearby aquatic plants area and twisted, while the GPS positioning signal has large error. To solve the problem, it predicts and corrects the GPS positioning error with improved Kalman filtering algorithm to improve the navigation accuracy.

\subsubsection{Sage-Husa adaptive Kalman filtering algorithm}

Sage-Husa adaptive filtering algorithm, also known as maximum a posterior estimator, estimates recursively updates the system noise and measurement noise using the measured data. Sage-Husa self-adaptive filtering algorithm can be described as $^{[13,14]}$ :

$$
\left\{\begin{array}{l}
X_{k \mid k-1}=\Phi_{k, k-1} \hat{X}_{k-1} \\
P_{k \mid k-1}=\Phi_{k, k-1} P_{k-1} \Phi_{k, k-1}^{T}+Q_{k-1} \\
K_{k}=P_{k, k-1} H_{k}^{T}\left(H_{k} P_{k, k-1} H_{k}^{T}+R_{k}\right)^{-1} \\
v_{k}=Z_{k}-H_{k} X_{k \mid k-1} \\
X_{k}=X_{k \mid k-1}+K_{k} v_{k} \\
P_{k}=\left(I-K_{k} H_{k}\right) P_{k, k-1} \\
R_{k}=\left(1-d_{k}\right) R_{k-1}+d_{k}\left(v_{k} v_{k}^{T}-H_{k} P_{k, k-1} H_{k}^{T}\right)
\end{array}\right.
$$


where, $P_{k}$ is the estimate mean square error; $P_{k, k-1}$ is one step prediction variance matrix; $K_{k}$ serves as the filter gain matrix; $v_{k}$ as the residual vector, and $R_{k}$ is the measurement noise covariance matrix, $d_{k}=(1-b) /\left(1-b^{k}\right)$. The forgetting factor $\mathrm{b}$ meets $0<b<1$ (the general value is $0.95-0.99$ ). With this algorithm, the calculation becomes simple with strong adaptability. In order to improve the filtering speed of dynamic response, the forgetting factor $b$ is added to limit the memory length of the filter. With the change of the measured values, the filter can make forecasts in a timely manner.

\subsubsection{Strong tracking Kalman filter algorithm}

In order to guarantee the convergence of the filter, certain accuracy can be sacrificed for the filtering stability, such as increasing the process noise of the system and observing the noise variance matrix, while a large number of un-modeled errors are included, the algorithm is simple and reliable. The strong tracking Kalman filter algorithm is put forward ${ }^{[15-17]}$, in front of the state estimation error covariance matrix is multiplied by a weighted coefficient $\lambda_{k}$.

$$
P_{k, k-1}=\lambda k \Phi_{k-1} P_{k-1} \Phi_{k-1}^{T}+Q_{k-1}
$$

where, $\lambda_{k}=\operatorname{diag}\left[\lambda_{1, k}, \lambda_{2, k}, \ldots, \lambda_{n, k}\right]$

$$
v_{0, k}= \begin{cases}v_{1} v_{1}^{T} & (k=1) \\ \frac{\rho v_{0, k-1}+v_{k} v_{k}^{T}}{1+\rho} & (k \geq 2,0 \leq \rho<1)\end{cases}
$$

This method has strong tracking ability of mutation, when filter reaches steady state and still maintains the ability, and holds low demands for initial values and noise statistical properties. When the state has mutations, the increase of the estimation error $v_{k} v_{k}^{T}$ will lead to the increase of the error variance matrix $v_{0, k}$ and weighted coefficient $\lambda_{i, k}$, so that the filter tracking ability has been enhanced, the reliability of the system improved.

\subsubsection{Improved adaptive filtering algorithm}

Advantages and disadvantages both existed in the Sage-Husa adaptive filtering algorithm and strong tracking Kalman filter algorithm, the former enjoys high precision but contains a large amount of calculation, hard to ensure real-time and stability; The latter has simple structure, high reliability, strong adaptive capacity, but low filtering precision. This paper will be organic combination of the two kinds of filtering algorithm, generating one filter algorithm which can both guarantee the filter convergence and keep high precision.

Because of the innovation sequence $v_{k} v_{k}^{T}$ being the sum of squares, which contains the information of actual estimation error, it can be used to describe the actual estimation error, and variance matrix $\mathrm{E}\left[v_{k} v_{k}^{T}\right]$ can be used to describe the theoretical prediction error

$$
\mathrm{E}\left[v_{k} v_{k}^{T}\right]=H P_{k, k-1} H^{T}+R_{k}
$$

Therefore, $v_{k}^{T} v_{k} \leq r t_{r}\left(\mathrm{E}\left[v_{k} v_{k}^{T}\right]\right)$ can be used to infer whether the filter convergence occurs or not. In the algorithm, $r \geq 1$ is the adjustable coefficient, $t_{r}$ is the matrix trace. When filter meets the convergence criterion, the Sage-HIusa algorithm conducts in its optimal state. If the conditions of the convergence criterion are not met, the actual error at this point is $r$ times greater than the theoretical predictions, indicating that the filter has divergent trends; by adjusting the value $P_{k, k-1}$ through the weighted coefficient $\lambda_{k}$, for the sake of better playing the role of the measured values to suppress the filtering divergence.

2.1.4 Algorithm simulation experiment analysis

All algorithms in this paper were implemented in the MATLAB R2010a under Windows 10 . The value of forgetting factor $\mathrm{b}$ in the adaptive Kalman filter is 0.96 . Simulation experiment is conducted for $500 \mathrm{~s}$, and the filtering effect of traditional Kaman filter and improved Kalman filter were showed in Figures 1 and 2. Compared with the traditional Kaman filter, the improved Kalman filter was more effective, the accurate in location error was promoted with higher stability.

In solving practical problems, the established mathematical model cannot reflect the actual physical process, when the model does not match with the measured values, the filter divergence will occur. The paper propose that on the basis of Sage-Husa filter algorithm, through the establishment of the weighted algorithm of one-step prediction of variance matrix $P_{k, k-1}$ of estimation error, filtering gain can be made to adapt to the observation data automatically, reducing the estimation error, thus achieving the purpose of inhibiting filtering divergence; therefore, it shows the advantages of more flexibility and reliability.

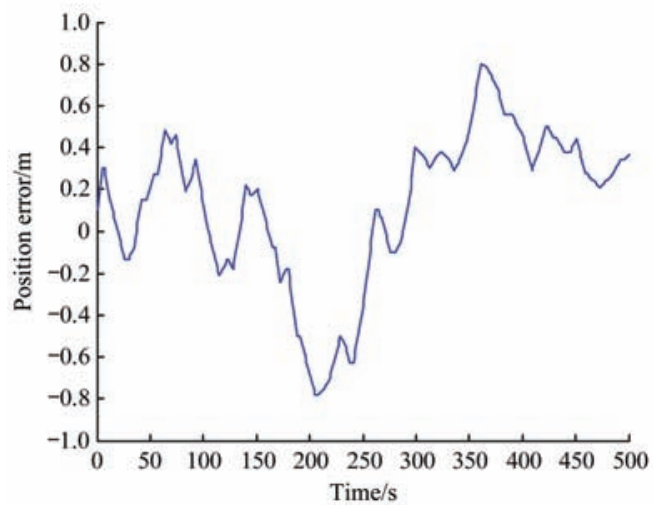

Figure 1 Position error of traditional Kalman filter

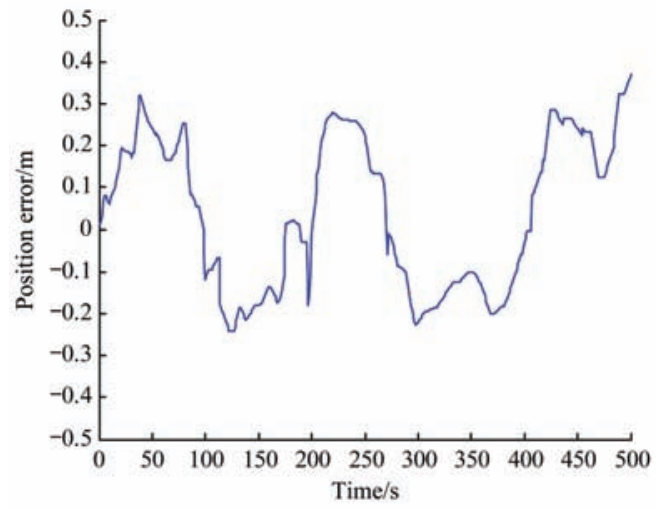

Figure 2 Position error of improved Kalman filter

\subsection{Path tracking algorithm}

Experiment boat is the autonomous surface vehicle (ASV) that does not have lateral thrusters, this is a kind of typical under-actuated system $^{[18,19]}$, in this paper, the linear active disturbances rejection control (LADRC) technique is applied to the track-keeping control of the boat path ${ }^{[20]}$. First, the structure can attain the heading angle of the expected boat with the goal of track-keeping, eliminate the track steady-state error caused by the wind flow interference by means of the integral term, the constructed heading angle of the expected ship as the reference input of LADRC, design the controller according to the course control structure, and transform the under-actuated ship track control into course control problem.

\subsubsection{Equation of motion of the boat}

Ignore the boat heave, pitch and roll, under the influence of the function of the uniform flow, considering the motion system of the under-actuated ship under the fixed coordinate system ${ }^{[21]}$ : 


$$
\left\{\begin{array}{l}
\dot{x}=v_{x} \cos \psi-v_{y} \sin \psi \\
\dot{y}=v_{y} \cos \psi-v_{x} \sin \psi \\
\dot{\psi}=r
\end{array}\right.
$$

where, the $x, y$ and $\psi$ are respectively indicating the position and heading angle of the boat under the fixed coordinate system, $v_{x}$ and $v_{y}$ are respectively indicating the component of the boat's ground speed under the hull coordinate, $r$ is the heading rate.

Construct the heading angle of expected boat ${ }^{[22,23]}$.

$$
\psi_{d}(t)=-k_{2} \int_{0}^{t} \tan h\left[\dot{y}(\zeta)+k_{1} \tan k\left(k_{0} y\right)\right] d \zeta
$$

where, $k_{0}>0, k_{1}>0$ and $k_{2}>0$ serve as design parameters, $k_{0}$ is used to compress the track deviation coordinate, to adjust the curve slope, $k_{1}$ is used to adjust the track convergence speed, $k_{2}$ for integral speed adjustment.

2.2.2 The design of path tracking controller

This article adopts the method of linear active disturbance rejection controller (LADRC) to design track controller, and apply the tracking differentiator (TD) in the input terminal of reference to arrange the transition process of the expected course angle, and extract its differential signal ${ }^{[24,25]}$. The structure of LADRC is shown as Figure 3. The heading control system is completely in line with the object form of the second order of LADRC. In the design of LADRC, input $\xi$ with the reference of $\psi_{d}$, arrange the transition process by tracking differentiator TD, extract its smooth transition signal $\xi_{1}$, and extract the differential of $\xi_{1}$, that is $\xi_{2}$. Making the heading angle $\psi$ as the control output, using the linear extended state observer (LESO) to estimate the controlled object $\psi$, the $z_{1}, z_{2}$ of state variables can track objects well, output $\psi$ and its differential signal $r, z_{3}$, which can give a real-time estimation of all the acceleration action $f\{\psi, r$, $\omega\}$ over the system, that is $z_{1} \rightarrow \psi, z_{2} \rightarrow r, z_{3} \rightarrow f\{\psi, r, \omega\}, \xi_{1}$ and $\xi_{2}$ produced by TD together with $z_{1}, z_{2}$ given by LESO form two error amount gas $e_{p}$ and $e_{d}$, the two error amount get error feedback $u_{0}$ after linear combination, and then form the controlled variable $u$ after the function of $z_{3}$ given by LESO, making the following control rate:

$$
\left\{\begin{array}{l}
u_{0}=k_{p} e_{p}+k_{d} e_{d} \\
u=\left(u_{0}-z_{3}\right) / b_{0}
\end{array}\right.
$$

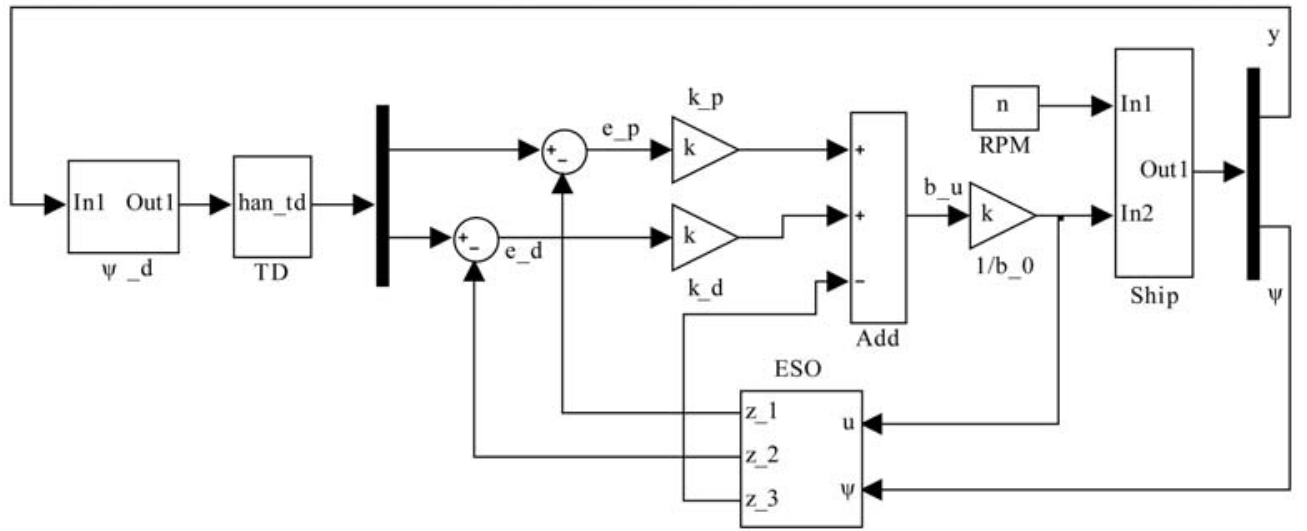

Figure 3 Structure of linear active disturbance rejection controller (LADRC)

\subsubsection{Straight-line tracking control simulation}

Choose any two points $\left(120.334^{\circ} \mathrm{N}, 31.438^{\circ} \mathrm{E}\right)$ and $\left(120.340^{\circ} \mathrm{E}\right.$, $31.440^{\circ} \mathrm{N}$ ) to constitute the planned straight-line route, set the initial position of the boat for $\left(120.335^{\circ} \mathrm{N}, 31.4378^{\circ} \mathrm{E}\right)$, the simulation results is shown as Figure 4 . In the figure, the continuous straight lines signify the planned path, dotted curve shows the tracking path of the boat. From the Figure 4, we can see that the initial position of the boat is not on the planned path, the boat is moving toward the specified path in the initial phase of tracking, and after a period of time, the boat sails on the planned path and keep stable.

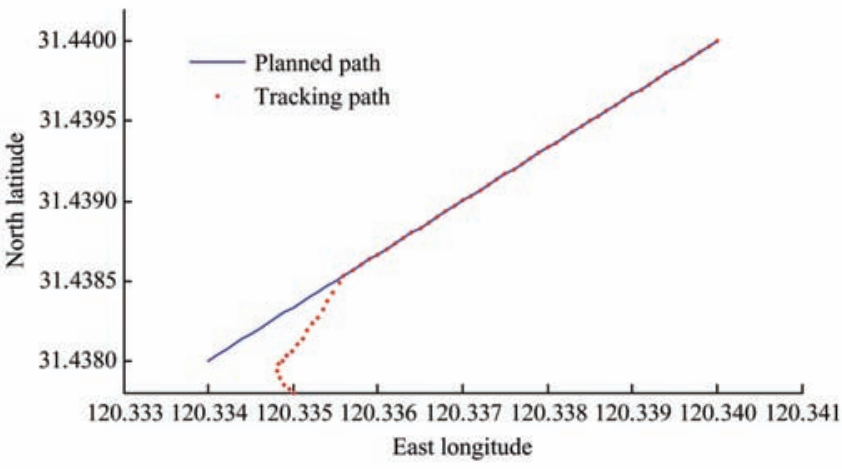

Figure 4 Straight line tracking control simulation

2.2.4 Broken line tracking control simulation Select any 3 points $\left(120.334^{\circ} \mathrm{E}, 31.438^{\circ} \mathrm{N}\right),\left(120.340^{\circ} \mathrm{E}\right.$, $\left.31.440^{\circ} \mathrm{N}\right)$ and $\left(120.338^{\circ} \mathrm{E}, 31.444^{\circ} \mathrm{N}\right)$ to combine a planned broken line path, set the initial position of the boat for $\left(120.335^{\circ} \mathrm{N}\right.$, $31.4378^{\circ} \mathrm{E}$ ), the simulation results are shown in Figure 5. From the figure, we can see that the initial position of boat is outside the planned path, while setting towards the initial stage and moving to the first planned path, once a turning point is detected, turn around and move to the next path. This indicates that the method can ensure the smooth and stable tracking realized by both the straight line sailing and the broken line sailing.

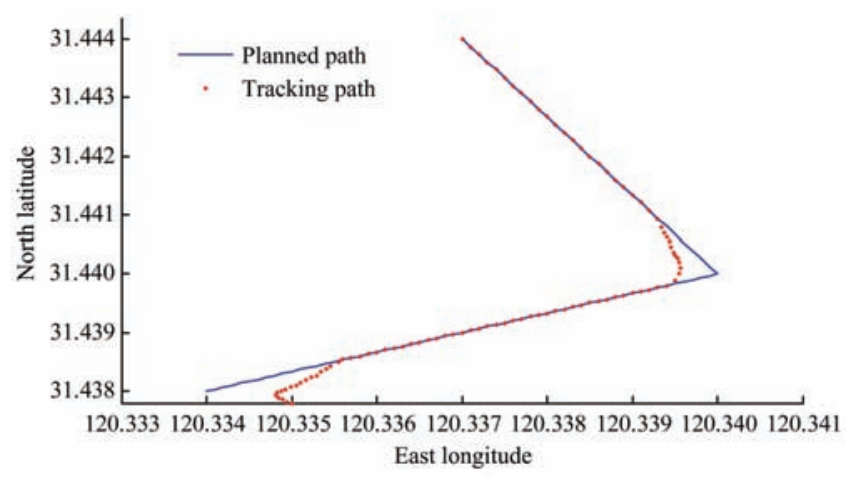

Figure 5 Broken line tracking control simulation

\subsection{Hardware design for experiment platform}

The boat used in the experiment was purchased in a domestic electronic business platform. The control module, water quality parameter measurement module and power-supply module were 
developed independently by the research group, and were integrated with the GPS positioning module and the GPRS-DTU packet data transmission module, the frame structure was shown in Figure 6. Equipped the above modules in the boat to form an automatic cruising system for water quality monitoring showed in Figure 7.

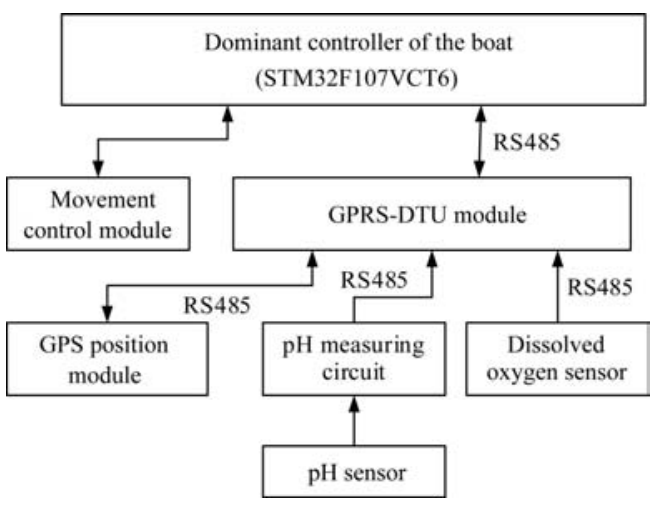

Figure 6 Frame structure diagram of the system

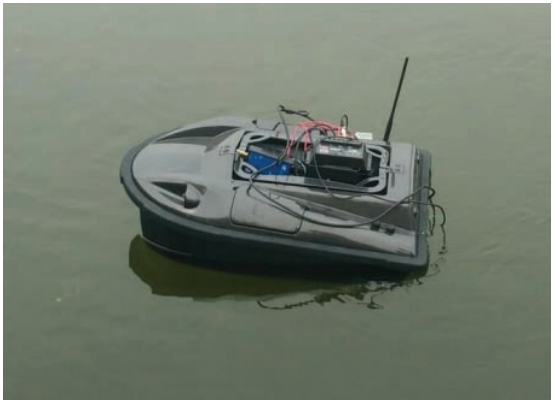

Figure 7 Automatic cruising boat for water quality monitoring

STM32F107VCT6 ARM was adopted as the dominant controller of the platform, and the Linux operation system was transplanted on it. The LCD screen shows the battery level and the electric map was used to record the path of the measuring boat. The latitudes and longitudes of the set path were sent to the boat's controlling ship via GPRS through the upper computer or Android mobile client.

The system selected RK-380PH-4733 high speed micro DC motor as the power source for the boat, and the maximum speed of the motor under the $12 \mathrm{~V}$ drive voltage is up to $1500 \mathrm{r} / \mathrm{min}$. The core driver board is L298N double H bridge DC motor-drive chip. And the drive model is controlled by PWM (Pulse Width Modulation).

The water quality parameter measurement module was composed of a digital dissolved oxygen probe and a $\mathrm{pH}$ sensor, which the dissolved oxygen probe adopted $\mathrm{HACH}$ LDO fluorescence probe with ModBus interface; the measuring range is $0-20 \mathrm{mg} / \mathrm{L}$ and response time is less than 20 seconds; the output result is the coding value for the dissolved oxygen and water temperature measurement and the practical measurement value can be gained via decoding. The $\mathrm{pH}$ sensor is the $\mathrm{PHJ}-100 \mathrm{~B}$ produced by Beijing Bohai Zhiyuan Technology Company.

GPS positioning module is the sixth GPS module NEO-6M that have 50 receiving channels and can research the satellites quickly. This module support TTL output and we have designed a conversion circuit to transfer TTL to RS485 signal.

The GPRS-DTU module adopted the WG-8010-485 module designed by Beijing Tiantong Chengye Company. We choose it for the following reasons: automatic connection, permanent supporting online and TCP communication, only a configuration for a long period and hard to be dropped, and rarely missing data. The system, through this module, can upload the water quality data and location information to the server, then through the server to set the boat's track and control it. The system structure is shown in Figure 8 .

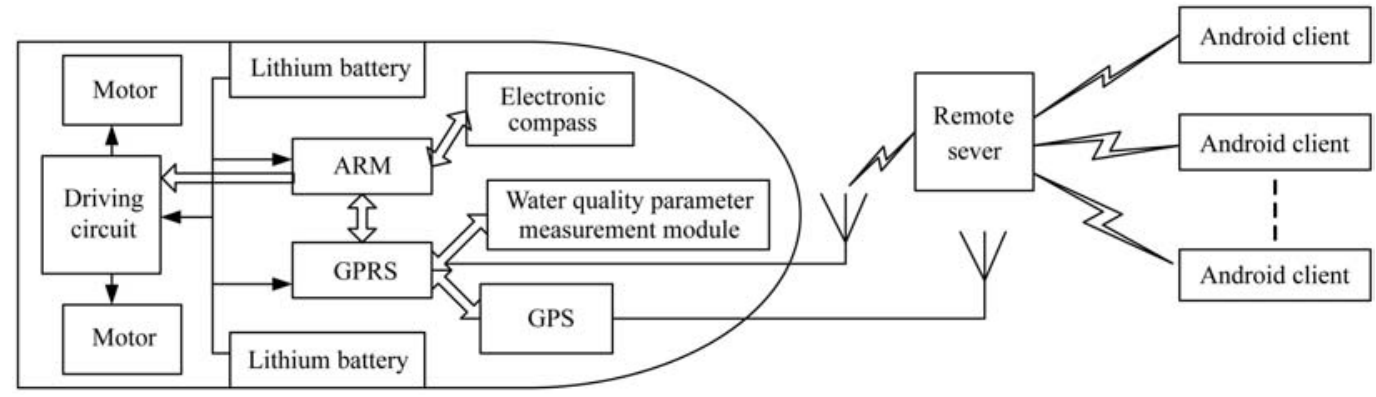

Figure 8 Structure diagram of automatic cruising boat

\subsection{Software design for the experiment system}

Server system is the center of the whole system, which not only record trajectories of measurement ship, calculating the navigation path but also send inquiry instruction for sensor acquisition to record the parameters of water quality and interact with the clients. The server takes Visual Studio 2010 as developing platform and programmed with VB.NET language.

We also designed Android mobile client for the convenience of monitoring. Meanwhile we can control the boat's movement manually ${ }^{[26,27]}$. The development environment of Android mobile client is Android SDK+JAVA JDK8+Eclipse10. The programming steps are as follows: first registered in the Android Manifest.xml file for network allowing, and then do the interface layout in activity_main.xml, where a linear layout is adopted. At last, program in the Main_Activity.java file. The monitoring result of Android mobile is shown in Figure 9.

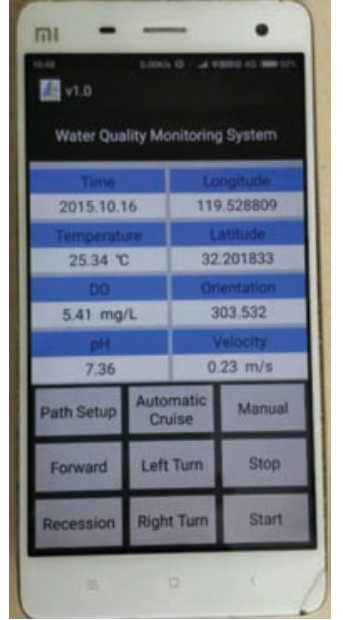

Figure 9 Android mobile client 


\section{Results and discussion}

On October 16, 2015, the experiment was carried out on the fish pond in Jiangsu University in order to verify the feasibility and effectiveness of the method.

\subsection{Experiment results and discussion on the automatic cruise} boat

Through the Android mobile client, seven measurement points' latitudes and longitudes were send to the boat's controlling ship via GPRS to finish the path planning for the boat's automatic cruise.

Conduct the experiment without introducing the filtering algorithm. The boat completed the entire measurement process according to the set path. And the host computer recorded the latitude and longitude information while cruising. The path was shown in Figure 10, the red line in the picture shows the set cruise path and the yellow one shows the actual path of the boat. When the signal is unstable or is interfered, the automatic cruise can complete the established route, but its accuracy and controlling efficiency need to be further improved. From the navigation chart we can see that from the starting point 1 to 2 measurement point, the track of the boat, from beginning point 1 to measurement point 2 , is relatively good; Form measurement point 2 to point 3 , though along the set route first, error became bigger and tracking efficiency lowered. The boat travel to the point 4 under the situation that it is far away from point 3 ; the tracking effect from point 3 to point 4 is ordinary common. From point 4 to point 5 and then to point 6 , the geomagnetic disturbance intensity becomes larger, and the tracking path appears larger error. Although the boat finally arrived at the measurement point 7 , its path is very awesome and the navigation effect is kind of bad. So from what mentioned above we can know that the original condition of the navigation controller, although simple, cannot eliminate the static error, and its anti-interference ability is weak. When the signal interference was large, the control system appears to be saturated, resulting in instability of the system. In the early stage of the experiment, the tracking effect is good and it can travel along the established route, but with the error accumulation and signal interference, its controller efficiency decreased, even lead to the boat tracker "out of control".

The Sage-Husa adaptive filter algorithm was applied in the automatic cruise boat and make the boat complete its measurement in the same set route. The route was shown in Figure 11. From the Figure we can see that the boat basically complete its route, and the navigation effect is good. The new approach improves the signal accuracy, speeding up the response speed of the navigation system and eliminates the influence of static error. Applying this to the automatic navigation system can improve its accuracy and anti-interference ability to ensure the control efficiency.

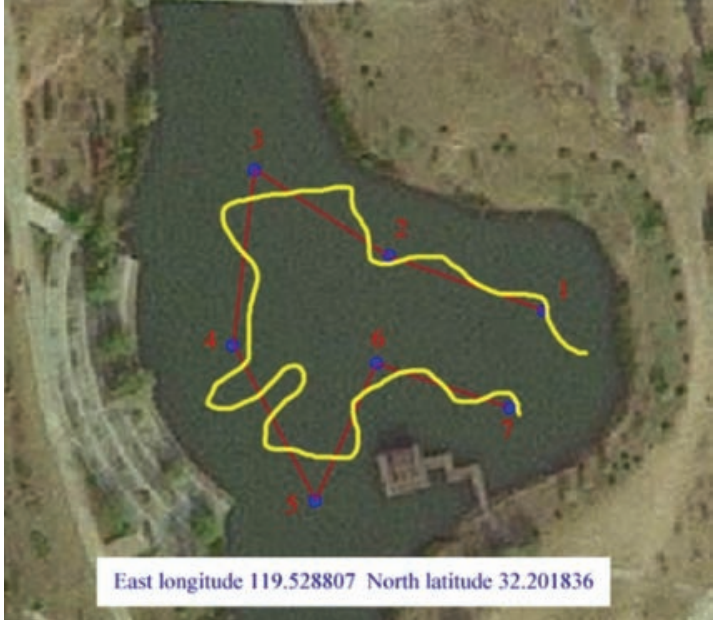

Note: the red line in the picture shows the set cruise path and the yellow one shows the actual path of the boat. The latitudes and longitudes showed on the electric map is the current location of the boat.

Figure 10 Navigation result in the original condition

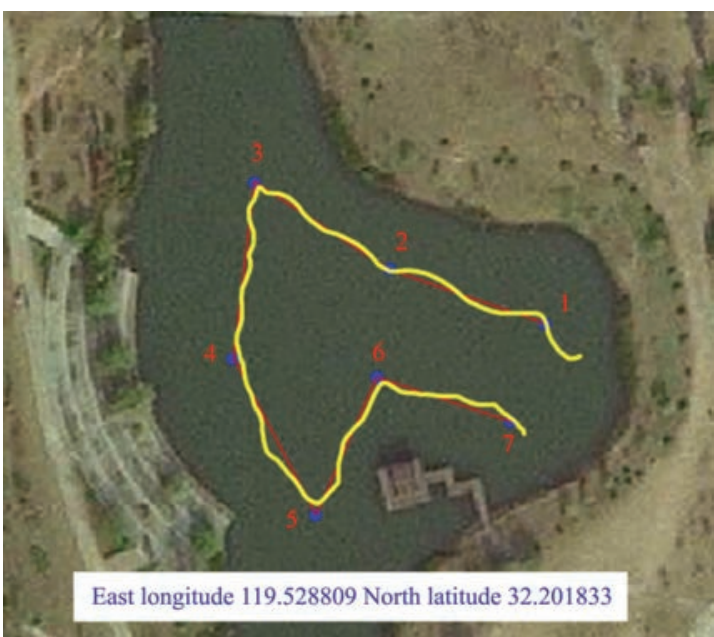

Note: the red line in the picture shows the set cruise path and the yellow one shows the actual path of the boat. The latitudes and longitudes showed on the electric map is the current location of the boat.

Figure 11 Navigation result with Sage-Husa adaptive Kalman filter

\subsection{Water quality parameter measurement}

In order to make a comparison between single point measurement and multi-point measurement, we adopt an aquaculture networking system made by the research group. And we use the dissolved oxygen probe that was same as the boat, $\mathrm{pH}$ sensors and transmitters to measure the single point in the center of the pond. The comparison between database-downloaded measured data and boat collected data is shown as Table 1 .

Table 1 Data of single-point and multi-point measurement

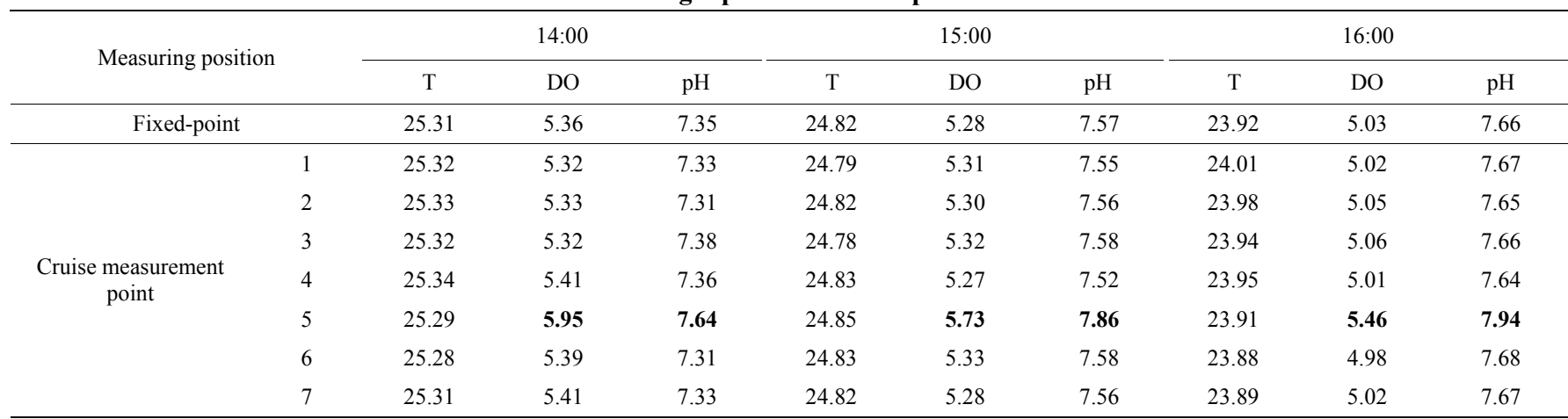

Note: T: water temperature; DO: Dissolved Oxygen. 
From the measurement point in the center of the pond, we can get the following factors. From 2:00 pm to 4:00 pm, the water temperature began to fall. Between 2:00 pm to 3:00 pm, the water temperature fall from $25.31^{\circ} \mathrm{C}$ to $24.82^{\circ} \mathrm{C}$, the percentage is about $2 \%$. $3: 00 \mathrm{pm}$ to $4: 00 \mathrm{pm}$, the water temperature fell about $3.6 \%$, from $24.82^{\circ} \mathrm{C}$ to $23.92^{\circ} \mathrm{C}$. That's because the weather temperature is highest at 2:00 pm, afterwards, the temperature falls down with the weakening in sunshine. Gradually, with time passing by, the falling speed become faster and dissolved oxygen is less, which reduces about $1.5 \%$ from 5.36 to 5.28 between $2: 00 \mathrm{pm}$ to 3:00 pm. And from 3:00 pm to 4:00 pm, the dissolved oxygen reduced about $4.7 \%$. Because from 2:00 pm to $4: 00 \mathrm{pm}$, the sunshine is weakening and the photosynthesis of phytoplankton in the fish pond also weakens, the releasing oxygen decreases, thus, also reduce. So the dissolved oxygen is gradually reduced; $\mathrm{pH}$ changed from 7.35 to 7.66 because the photosynthesis of phytoplankton consumes carbon dioxide, and the content of carbonate in water decreases, so the value of $\mathrm{pH}$ increased gradually. However, the photosynthesis between 2:00 pm and 3:00 pm is stronger than that between 3:00 pm and 4:00 pm, so the improving speed of $\mathrm{pH}$ is falling.

Data from the 7 locations of the measurement and central pond measurement data indicates that the water temperature in the pond is basically the same in three time periods. However, in the No.5 measurement area, the dissolved oxygen in three time periods is respectively higher about $10.2 \%, 8.5 \%$ and $8.3 \%$ than other 6 measuring areas because there are almost $4 \mathrm{~m}^{2}$ aquatic plants around No.5 measuring areas. The photosynthesis of aquatic plants releases more oxygen than other waters, so the content of dissolved oxygen around here is higher than the other waters, but with the weakening of photosynthesis, the dissolved oxygen in this area, though higher than other areas, will lower its higher range. The $\mathrm{pH}$ value in No.5 measurement area in three time periods is higher about $4.1 \%, 3.8 \%$ and $3.7 \%$ than other water areas. It is also because that photosynthesis consumes more carbon dioxide, the carbonate content in this area is lower than other areas, so that the $\mathrm{pH}$ value is higher than other areas.

In order to study the difference degree of DO of aquatic plants area and no aquatic plants area, we download $1 \mathrm{~d}$ measurement data of the No.5 and the fixed measurement point from monitoring system database, and carry on the variance analysis for 2 sets of data. The results are shown in Table 2.

Table 2 Variance analysis of 2 sets of measurement data

\begin{tabular}{cccccc}
\hline $\begin{array}{c}\text { Source of } \\
\text { difference }\end{array}$ & $\begin{array}{c}\text { Sum of } \\
\text { Square (SS) }\end{array}$ & $\begin{array}{c}\text { degree of } \\
\text { freedom (df) }\end{array}$ & $\begin{array}{c}\text { Mean Square } \\
(\mathrm{MS})\end{array}$ & $F$ & $P$ \\
\hline Between groups & 47.47 & 4 & 11.87 & 5.55 & 2.76 \\
Error & 53.50 & 25 & 2.14 & & \\
Total & 100.97 & 29 & & & \\
\hline
\end{tabular}

As seen in Table 2, $F_{0.05}=2.76<5.55$, which is below the significant level $\alpha=0.05$. Thus, we suppose that there have significant differences of the DO near $4 \mathrm{~m}^{2}$ area with and without aquatic plants.

\section{Conclusions}

An automatically cursing system for water quality monitoring system using improved Kalman filtering algorithm and path tracking algorithm are designed to monitor the water quality parameters in a large area of culture areas. It solved the problem that single point measurement cannot reflect the overall water quality of the fishpond and the high cost of the multi point measurement. The Android mobile client designed in this paper will enable managers get the water quality parameters of any areas whenever they are and provide some reference for decision making, which has its own applied values. This system is not only suitable for aquaculture, but also can be applied to the water quality monitoring of water plant and emergency water pollution.

\section{Acknowledgements}

The study was financially supported by the National Natural Science Foundation of China (31172243), the Agricultural Science and Technology Support Program of Jiangsu Province (BE2013402), the Priority Academic Program Development of Jiangsu Higher Education Institutions (PAPD, NO.6-2011).

\section{[References]}

[1] Rathi S, Gupta R A simple sensor placement approach for regular monitoring and contamination detection in water distribution networks. Ksce Journal of Civil Engineering 2016; 20: 597-608. doi: 10.1007/ s12205-015-0024-X

[2] Huang X, Yi J, Chen S, Zhu X. A wireless sensor network-based approach with decision support for monitoring lake water quality. Sensors, 2015; 15: 29273-29296. doi: 10.3390/s151129273

[3] Keum J, Kaluarachchi J J. Development of a decision-making methodology to design a water quality monitoring network. Environmental Monitoring and Assessment 2015, 187. doi: 10.1007/s10661-015-4687-z

[4] Skadsen J, Janke R, Grayman W, Samuels W, Tenbroek M, Steglitz B, et al Distribution system on-line monitoring for detecting contamination and water quality changes. Journal / American Water Works Association, 2008; 100: 81-94.

[5] Eliades D G, Polycarpou M M. In multi-objective optimization of water quality sensor placement in drinking water distribution networks, 2007 9th European Control Conference, ECC 2007, July 2, 2007 - July 5, 2007, Kos, Greece, 2015; Institute of Electrical and Electronics Engineers Inc.: Kos, Greece, pp.1626-1633.

[6] Simbeye D S, Yang S F. Water quality monitoring and control for aquaculture based on wireless sensor networks. Journal of Networks, 2014; 9: 840-849. doi: 10.4304/jnw.9.4.840-849

[7] Gustilo R C, Dadios E P. Machine vision support system for monitoringwater quality in a small scale tiger prawn aquaculture. Journal of Advanced Computational Intelligence and Intelligent Informatics, 2016; 20: 111-116.

[8] Bergquist D C, Heuberger D, Sturmer L N, Baker S M. Continuous water quality monitoring for the hard clam industry in florida, USA. Environmental Monitoring and Assessment, 2009; 148: 409-419. doi: 10.1007/s10661-008-0171-3

[9] Luo H, Li G, Peng W, Song J, Bai Q. Real-time remote monitoring system for aquaculture water quality. Int J Agric \& Biol Eng, 2015; 8(6): 136-143. doi: 10.3965/j.ijabe.20150806.1486

[10] Dong J, Wang G, Yan H, Xu J, Zhang X. A survey of smart water quality monitoring system. Environmental Science and Pollution Research International, 2015; 22: 4893-4906. doi: 10.1007/s11356-014-4026-X

[11] Chung W-Y, Yoo J-H. Remote water quality monitoring in wide area. Sensors and Actuators B: Chemical, 2015; 217: 51-57. doi: 10.1016/j.snb.2015.01.072

[12] Sicard C, Glen C, Aubie B, Wallace D, Jahanshahi-Anbuhi S, Pennings K, et al. Tools for water quality monitoring and mapping using paper-based sensors and cell phones. Water Research, 2015; 70: 360-369. doi: 10.1016/j.watres.2014.12.005

[13] Sun J, Xu X S, Liu Y T, Zhang T, Li Y. Fog random drift signal denoising based on the improved ar model and modified sage-husa adaptive kalman filter. Sensors, 2016; 16: 1073. doi: 10.3390/s16071073

[14] Gao, X.D.; You, D.Y.; Katayama, S. Seam tracking monitoring based on adaptive kalman filter embedded elman neural network during high-power fiber laser welding. IEEE Transactions on Industrial Electronics, 2012; 59: 4315-4325. doi: 10.1109/tie.2012.2193854

[15] Xia B Z, Wang H Q, Wang M W, Sun W, Xu Z H, Lai Y Z. A new 
method for state of charge estimation of lithium-ion battery based on strong tracking cubature kalman filter. Energies, 2015; 8: 13458-13472. doi: 10.3390/en81212378

[16] Huang W, Xie H S, Shen C, Li J P. A robust strong tracking cubature kalman filter for spacecraft attitude estimation with quaternion constraint. Acta Astronautica, 2016; 121: 153-163. doi: 10.1016/j.actaastro. 2016.01.009

[17] Hu G G, Gao S S, Zhong Y M, Gao B B, Subic A. Modified strong tracking unscented kalman filter for nonlinear state estimation with process model uncertainty. International Journal of Adaptive Control and Signal Processing, 2015; 29: 1561-1577. doi: 10.1002/acs.2572

[18] Motwani A, Liu W W, Sharma S, Sutton R, Bucknall R. An interval kalman filter-based fuzzy multi-sensor fusion approach for fault-tolerant heading estimation of an autonomous surface vehicle. Proceedings of the Institution of Mechanical Engineers Part M-Journal of Engineering for the Maritime Environment, 2016; 230: 491-507. doi: 10.1177/ 1475090215596180

[19] Xu H T, Soares C G. Vector field path following for surface marine vessel and parameter identification based on ls-svm. Ocean Engineering, 2016; 113: 151-161. doi: 10.1016/j.oceaneng.2015.12.037

[20] Xiao H, Wang C, Han Y, Pan W, Zhou F, Yang Y, Li J. In Design of ship straight-line tracking controller based on auto disturbance rejection control technique. 8th World Congress on Intelligent Control and Automation, WCICA 2010, Jinan, China. July 7-9, 2010; pp 2559-2564.

[21] Jin X. Fault tolerant finite-time leader follower formation control for autonomous surface vessels with los range and angle constraints. Automatica, 2016; 68: 228-236. doi: 10.1016/j.automatica.2016.01.064

[22] Zuo L, Yan W S, Cui R X, Gao J. A coverage algorithm for multiple autonomous surface vehicles in flowing environments. International Journal of Control Automation and Systems, 2016; 14: 540-548. doi: 10.1007/s12555-014-0454-0

[23] Shojaei K. Observer-based neural adaptive formation control of autonomous surface vessels with limited torque. Robotics and Autonomous Systems, 2016;78: 83-96. doi:10.1016/j.robot.2016.01.005

[24] Han Y, Xiao H, Wang C, Zhou F. In design and simulation of ship course controller based on auto disturbance rejection control technique, 2009 IEEE International Conference on Automation and Logistics, ICAL 2009, Shenyang, China, August 5-7, 2009; pp 686-691.

[25] Chen W, Zhou F, Li Y, Song R. In the ship nonlinear course system control based on auto disturbance rejection controller. 7th World Congress on Intelligent Control and Automation, WCICA'08, Chongqing, China, June 25-27, 2008; pp 6454-6458.

[26] Stradolini F, Riario S, Boero C, Baj-Rossi C, Taurino I, Surrel G, et al Wireless monitoring of endogenous and exogenous biomolecules on an android interface. IEEE Sensors Journal, 2016; 16: 3163-3170. doi: 10.1109/jsen.2016.2524631

[27] Kim K-W. An efficient implementation of key frame extraction and sharing in android for wireless video sensor network. KSII Transactions on Internet and Information Systems, 2015; 9: 3357-3376. doi: $10.3837 /$ tiis.2015.09.005 